Mots. Les langages du politique

\title{
Bibliographie thématique. Sport et politique
}

Dominique DESMARCHELIER

\section{(2) OpenEdition}

\section{Journals}

Édition électronique

URL : https://journals.openedition.org/mots/17293

DOI : $10.4000 /$ mots. 17293

ISSN : 1960-6001

\section{Éditeur}

ENS Éditions

\section{Édition imprimée}

Date de publication : 1 juillet 2007

Pagination : 65-67

ISBN : 978-2-84788-112-7

ISSN : 0243-6450

\section{Référence électronique}

Dominique DESMARCHELIER, «Bibliographie thématique. Sport et politique », Mots. Les langages du politique [En ligne], 84 | 2007, mis en ligne le 01 juillet 2009, consulté le 24 avril 2022. URL : http:// journals.openedition.org/mots/17293; DOI : https://doi.org/10.4000/mots.17293 


\section{Bibliographie thématique Sport et politique}

ABÉLÈS Marc, 1989, «Rituels et communication politique moderne », Hermès, $n^{\circ} 4$. ANSCOMBRE Jean-Claude, 1995, Théorie des Topoï, Paris, Kimé, $224 \mathrm{p}$.

AMOSSY Ruth éd., 1999, Images de soi dans le discours. La construction de l'ethos, Lausanne, Paris, Delachaux \& Niestlé, 215 p.

- 2000, L'argumentation dans le discours, Paris, Nathan, 275 p.

- éd., 2002, Pragmatique et analyse des textes, Tel-Aviv, Presses de l'Université de Tel-Aviv, $300 \mathrm{p}$.

AUGÉ Marc, 1982, « Football. De l'histoire sociale à l'anthropologie religieuse », Le Débat, $\mathrm{n}^{\circ} 19,1982$, p. 59-67.

BALANDIER Georges, 1992, Le pouvoir sur scènes, Paris, Balland, 248 p.

BONIFACE Pascal, 1998, Géopolitique du football, Bruxelles, Complexe, 205 p.

BONNAFOUS Simone, DESMARCHELIER Dominique, 1999, "Quand les députés coupent le RESEDA», Mots. Les langages du politique, $\mathrm{n}^{\circ}$ 60, p. 93-109.

BONNAFOUS Simone, CHIRON Pierre, DUCARD Dominique, LEVY Carlos éd., 2003, Argumentation et discours politique, Rennes, Presses universitaires de Rennes, $272 \mathrm{p}$.

BOUET Michel, 1995, Signification du sport, Paris, L'Harmattan, $670 \mathrm{p}$.

BOURDON Jérôme, 1992, "Le programme de télévision et l'identité nationale», Médiaspouvoirs, $\mathrm{n}^{\circ} 28, \mathrm{p}$. 5-13. $^{2}$.

BOURG Jean-François, 1988, Le sport en otage, Paris, La Table Ronde, $224 \mathrm{p}$.

- 1990, "L'information sportive sur un marché monopolistique», Médiaspouvoirs, $\mathrm{n}^{\circ} 18$, p. 29-38.

— 1999, "Le sport à l'épreuve du marché », Géopolitique, n 66, p. 51-58.

BRETON Philippe, 1996, L'argumentation dans la communication, Paris, La Découverte, $116 \mathrm{p}$.

BROHM Jean-Marie, 1992, Sociologie politique du sport, Nancy, Presses universitaires de Nancy, $399 \mathrm{p}$.

- 1993, Les meutes sportives, Paris, L'Harmattan, 575 p.

BROMBERGER Christian, 1995, Le match de football. Ethnologie d'une passion partisane à Marseille, Naples et Turin, Paris, MSH, $136 \mathrm{p}$.

— 1998, Football, la bagatelle la plus sérieuse du monde, Paris, Bayard, 125 p.

BRUGIDOU Mathieu, 1995, L'élection présidentielle. Discours et enjeux politiques, Paris, L'Harmattan, $299 \mathrm{p}$.

CHARAUDEAU Patrick, 1997, Le discours d'information médiatique. La construction du miroir social, Paris, Nathan, $286 \mathrm{p}$.

- 2005, Le discours politique. Les masques du pouvoir, Paris, Vuibert, 255 p.

COMERON Manuel, GOVAERT Serge, 1995, Foot et violence. Politiques, stades et hooligans. Heysel 85, Bruxelles, De Boeck, $199 \mathrm{p}$. 
COTTERET Jean-Marie, MOREAU René et al., 1969, Recherches sur le vocabulaire du Général de Gaulle. Analyse statistique des allocutions radiodiffusées, 1958-1965, Paris, Armand Colin, $247 \mathrm{p}$.

CUMINAL Isabelle et al., 1997, Le Pen, les mots. Analyse d'un discours d'extrême droite, Paris, La Découverte, $279 \mathrm{p}$.

DARBON Sébastien éd., 1999, Rugby d'ici. Une manière d'être au monde, Paris, Autrement, $221 \mathrm{p}$.

DERÈZE Gérard, 1994, "Quand le sport monte en ligne... Sport, médias et imaginaire wallon », L'imaginaire wallon, L. Courtois, J. Pirotte éd., Louvain-la-Neuve, Fondation wallonne, p. 265-274.

- 1996, "Le stade de football. Essai sur la construction sociale et journalistique d'un espace commun », Études de communication, $\mathrm{n}^{\circ}$ 18, p. 89-111.

DIANA Jean-François, LOCHARD Guy éd., 2004, Le sport médiatisé. Du voir au savoir, Média Morphoses, $\mathrm{n}^{\circ}$ 11, Paris, INA.

DUNNING Éric, ELIAS Norbert, 1994, Sport et civilisation, Paris, Fayard, 392 p.

FINNISS-BOURSIN Françoise, 1992, Les discours de vœux des présidents de la République. La France au fond des yeux, Paris, Librairie générale de droit et de jurisprudence, $446 \mathrm{p}$.

FONTANIER Pierre, 1977 [1821], Les figures du discours, introd. G. Genette, Paris, Flammarion, $505 \mathrm{p}$.

GABASTON Pierre, LECONTE Bernard éd., 2000, Sport et télévision. Regards croisés, Paris, L'Harmattan, $489 \mathrm{p}$.

HUESCA Roland, 1999, "Sport, la passion manipulée», Cultures en mouvement, n¹9, p. 33 .

LABBÉ Dominique, 1983, François Mitterrand. Essai sur le discours, Grenoble, La Pensée sauvage, $191 \mathrm{p}$.

- 1990, Le vocabulaire de François Mitterrand, Paris, Presse de la FNSP, 326 p.

LECONTE Bernard, VIGARELLO Georges éd., 1998, Le spectacle du sport, Communication, $\mathrm{n}^{\circ}$ 67, Paris, Le Seuil, $215 \mathrm{p}$.

LEMIEUX Cyril, MIGNON Patrick éd., 2000, Sport et politique, Politix, $\mathrm{n}^{\circ} 50$, Paris, Hermès Science Publications, $205 \mathrm{p}$.

LOCHARD Guy, 2005, L'information télévisée. Mutations professionnelles et enjeux citoyens, Paris, Vuibert-INA, $220 \mathrm{p}$.

MAYAFFRE Damon, 2004, Paroles de président. Jacques Chirac (1995-2003) et le discours présidentiel sous la Ve République, Paris, Champion, $291 \mathrm{p}$.

MIGNON Patrick, 1999, « Le sport, facteur de paix ou de guerre à l'époque contemporaine », Géopolitique, n 66, p. 45-50.

PERELMAN Chaïm, OLBRECHTS-TYTECA Lucie, 2000 [1988], Traité de l'argumentation, Bruxelles, Université de Bruxelles, 734 p.

PIVATO Stefano, 1994, Les enjeux du sport, Paris, Florence, Casterman, Giunti, 157 p.

PLANTIN Christian, 1990, Essais sur l'argumentation, Paris, Kimé, 351 p.

— éd., 1990, Lieux communs, topoï, stéréotypes, clichés, Paris, Kimé, 522 p. 
POCIELLO Christian éd., 1981, Sport et société. Approche socio-culturelle des pratiques, Paris, Vigot, $377 \mathrm{p}$.

- 1995, Les cultures sportives, Paris, PUF, $287 \mathrm{p}$.

Quasimodo, 1996, Sport et nationalisme, $\mathrm{n}^{\circ}$ 1, octobre, $31 \mathrm{p}$.

Quasimodo, 1997, Nationalismes sportifs, $\mathrm{n}^{\circ} 3-4$, printemps, $176 \mathrm{p}$.

SAFRA Jean-Marie, 1986, "Les dérives du journalisme sportif», Médiaspouvoirs, $\mathrm{n}^{\circ} 3$, p. $79-84$.

SMITH Andy, 2001, La passion du sport. Le football, le rugby et les appartenances en Europe, Rennes, Presses universitaires de Rennes, $126 \mathrm{p}$.

VIALLON Philippe, 1996, L'analyse du discours de la télévision, Paris, PUF (Que sais-je?), $127 \mathrm{p}$.

VION Robert, 1992, La communication verbale, Analyse des interactions, Paris, Hachette, $302 \mathrm{p}$.

— éd., 1998, Les sujets et leurs discours. Énonciation et interaction, Aix-en-Provence, Université de Provence, $263 \mathrm{p}$.

Dominique Desmarchelier 